\title{
A MYB-related transcription factor from sheepgrass, LCMYB2, promotes seed germination and root growth under drought stress
}

Pincang Zhao ${ }^{1,2+}$, Shenglin Hou ${ }^{1,3+}$, Xiufang Guo ${ }^{1 \dagger}$, Junting Jia ${ }^{1,5}$, Weiguang Yang ${ }^{1,4}$, Zhujiang Liu', Shuangyan Chen ${ }^{1}$, Xiaoxia Li ${ }^{1}$, Dongmei Qi ${ }^{1}$, Gongshe Liu ${ }^{1 *}$ and Liqin Cheng ${ }^{1 *}$

\begin{abstract}
Background: Drought is one of the most serious factors limiting plant growth and production. Sheepgrass can adapt well to various adverse conditions, including drought. However, during germination, sheepgrass young seedlings are sensitive to these adverse conditions. Therefore, the adaptability of seedlings is very important for plant survival, especially in plants that inhabit grasslands or the construction of artificial grassland.

Results: In this study, we found a sheepgrass MYB-related transcription factor, LCMYB2 that is up-regulated by drought stress and returns to a basal level after rewatering. The expression of LCMYB2 was mainly induced by osmotic stress and was localized to the nucleus. Furthermore, we demonstrate that LCMYB2 promoted seed germination and root growth under drought and ABA treatments. Additionally, we confirmed that LCMYB2 can regulate $L C D R E B 2$ expression in sheepgrass by binding to its promoter, and it activates the expression of the osmotic stress marker genes AtDREB2A, AtLEA14 and AtP5CS1 by directly binding to their promoters in transgenic Arabidopsis.

Conclusions: Based on these results, we propose that LCMYB2 improves plant drought stress tolerance by increasing the accumulation of osmoprotectants and promoting root growth. Therefore, LCMYB2 plays pivotal roles in plant responses to drought stress and is an important candidate for genetic manipulation to create droughtresistant crops, especially during seed germination.
\end{abstract}

Keywords: LCMYB2, Seed germination, Root growth, Osmoprotectant

\section{Background}

Seed germination and seedling establishment are the most critical stages in the life cycle of plants [1], also the germination and young seedlings establishment phases for most plants are the most sensitive to stressful conditions, such as drought. Drought has been known as the most important factor limiting plant growth and productivity, particularly in arid and semiarid regions. Thus, the research on seed germination and seedling establishment under

\footnotetext{
* Correspondence: liugs@ibcas.ac.cn; lqcheng@ibcas.ac.cn

${ }^{\dagger}$ Pincang Zhao, Shenglin Hou and Xiufang Guo contributed equally to this work.

${ }^{1}$ Key Laboratory of Plant Resources, Institute of Botany, The Chinese

Academy of Sciences, Beijing, China

Full list of author information is available at the end of the article
}

drought stress is required not only for evaluating and breeding the ecological adaptation of the species, but also for developing effective strategies for restoration and application arid and semiarid grassland.

Drought typically has complex ramifications that impose hyperosmotic and ionic stresses on cells by disrupting the water potential gradient of the soil-root-plantatmosphere continuum [2]. Plants, especially those constantly growing in severe environments, have evolved many strategies to cope with abiotic stress. Generally, plants adopt either stress tolerance or stress avoidance strategies. For example, establishing deeper roots, which helps roots absorb water from deeper underground in drought conditions, is an avoidance strategy $[2,3]$.

(c) The Author(s). 2019 Open Access This article is distributed under the terms of the Creative Commons Attribution 4.0 International License (http://creativecommons.org/licenses/by/4.0/), which permits unrestricted use, distribution, and 
Controlling stomata aperture to reduce transpiration and accumulating osmoprotectants (e.g. proline or soluble sugars) are usually thought to be stress tolerance strategies [4-7].

The primary signal caused by drought is osmotic stress, which is a signal that overlaps with that of salt stress and increases the accumulation of phytohormone abscisic acid (ABA) $[8,9]$. Endogenous ABA plays a critical role in regulating stomatal aperture and inducing the biosynthesis of osmolytes through signaling cascades [10-13]. ABA increases, it binds to soluble ABA receptors (PYR/PYL/RCAR), and together they bind to and inhibit plant protein phosphatases (PP2Cs) [14-17]. The inactive PP2Cs are released from SnRK2 kinases, activating them so that they phosphorylate and activate downstream transcription factors and effectors in ABA response pathways [2, 18, 19].

Many types of transcription factors, such as basic Leucine Zipper (bZIP); NAM, ATAF and CUC transcription factor (NAC); APETUAP2/Ethylene-Responsive-Element Binding Protein (AP2/ERF), and MYB DNA-binding domain protein $(\mathrm{MYB})$, are involved in drought stress responses [20-22]. MYB transcription factors are reported to play a role in multiple functions, including metabolism, cell fate and identity, developmental processes and responses to biotic and abiotic stresses during the plant life cycle [23]. Members of the MYB transcription factor family are divided into four classes depending on the number of adjacent repeats (one, two, three or four) [23]. It has been reported that AtMYB60 and AtMYB61 regulate stomatal movement and plant drought tolerance in opposite manners [24, 25]. MYB96, which is involved in the development of lateral roots, regulates drought response by integrating $A B A$ and auxin signals [26]. In addition, the overexpression of AtMYB44, StMYB1R-1, TaMYB33 or TaPIMP1 improved drought stress tolerance in transgenic plants through different mechanisms [27-30]. An important discovery, that a $366 \mathrm{bp}$-insertion including three MYB cis-elements in the promoter of ZmVPP1 confers drought-inducible expression to ZmVPP1 in the variant, indicates that MYB-type transcription factors have significant functions in drought response [31]. Sheepgrass, which is widely distributed in Eurasia, adapts well to drought, cold, saline and alkaline conditions [32, 33]. To explore the mechanism that underlies the abiotic stress tolerance of sheepgrass, several transcriptome analyses have been performed in the past few years [32-35], and several genes identified by transcriptome analyses have actually enhanced the abiotic stress tolerance of transgenic plants [36-42]. Although MYB transcription factors play pivotal roles in drought responses, there is still no report on MYB proteins from sheepgrass that elucidates their contributions to sheepgrass drought tolerance. In a previous study, we revealed that 15 MYB and MYB-related transcription factors that are involved in drought stress response [35]. A transcript (contig41859), named Leymus chinensis MYB DNAbinding domain protein 2 (LcMYB2) is largely induced by drought and was selected for further analysis. The transcript levels of $L c M Y B 2$ were enhanced under manninol, salt, $A B A$ and cold treatments. The results of subcellular localization of 35S-LcMYB2-GFP and the distribution of the $\beta$-galactosidase activity of GAL4-BD-LcMYB2 indicate that LcMYB2 localizes to the nucleus and activates the transcription of lacZ. Chromatin immunoprecipitation (CHIP) analysis using anti-LcMYB antibodies showed that LcMYB2 can bind to the promoters of Leymus chinensis Dehydration Responsive Element Binding Protein 2(LCDREB2), Arabidopsis thaliana Dehydration Responsive Element Binding Protein 2A(AtDREB2A), Arabidopsis thaliana $\triangle 1$-Pyrroline-5-carboxylate synthetas (AtP5CS1) and Arabidopsis thaliana Late-embryogenesis-abundant protein (AtLEA14). Overexpressing $L c M Y B 2$ in $A$. thaliana promotes seed germination and enhances root growth under osmotic and ABA treatment and further increases soluble sugar and proline content with $300 \mathrm{mmol} / \mathrm{L}$ mannitol treatment. In addition, transgenic seedlings performed better than wild-type under natural drought stress. Taken together, these results indicated that $L c M Y B 2$ plays critical roles in the drought responses of sheepgrass through both avoidance and tolerance strategies. Furthermore, this work provides important information for understanding the intrinsic characteristics of sheepgrass drought tolerance and supplies an important candidate gene for improving drought stress tolerance with genetic engineering.

\section{Results}

\section{LCMYB2 expression pattern analysis}

Based on 454 high throughput sequencing and expression profile analyses of sheepgrass under drought stress, we found $15 \mathrm{MYB}$ and MYB-related transcription factors that were responsive to changes of water content in plant tissues [32, 35]. Contig41859, which was up-regulated by drought stress and named $L c M Y B 2$, was a MYB-related transcription factor with unknown function that attracted our attention (Additional file 1: S1).

LcMYB2 is highly induced by $300 \mathrm{mM}$ mannitol at the 8th hour after treatment (Fig. 1a), whereas it is relatively slower responding to salt and cold stress $(24 \mathrm{~h}$, Fig. 1b, c). However, it is quickly upregulated by ABA treatment (Fig. 1d). The maximal level of mRNA accumulation under mannitol treatment is higher than under salt, cold and $\mathrm{ABA}$ treatments, indicating that $L c M Y B 2$ mainly functions in response to osmotic stress. Furthermore, the expression level of $L c M Y B 2$ in different organs is also detected under normal growth conditions. The results show that $L c M Y B 2$ has the highest transcript level in roots (Fig. 1e). Based on these combined results, we 

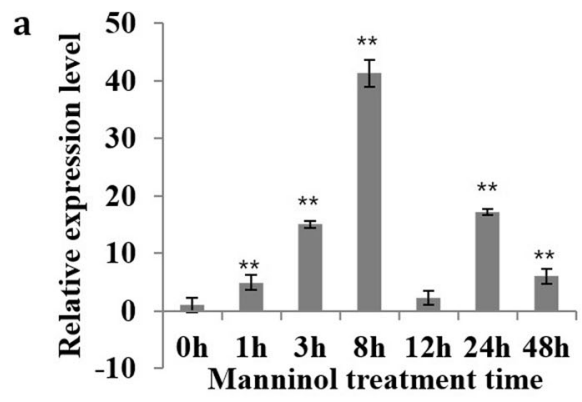

c

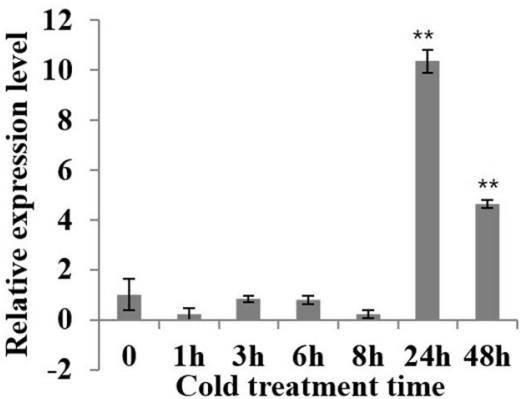

b

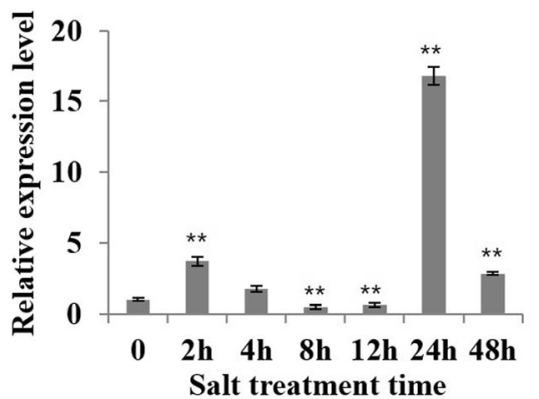

d

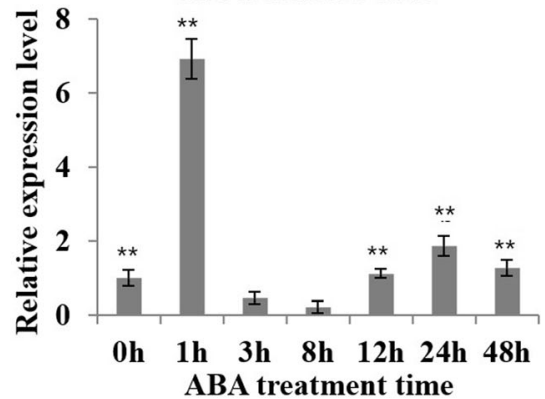

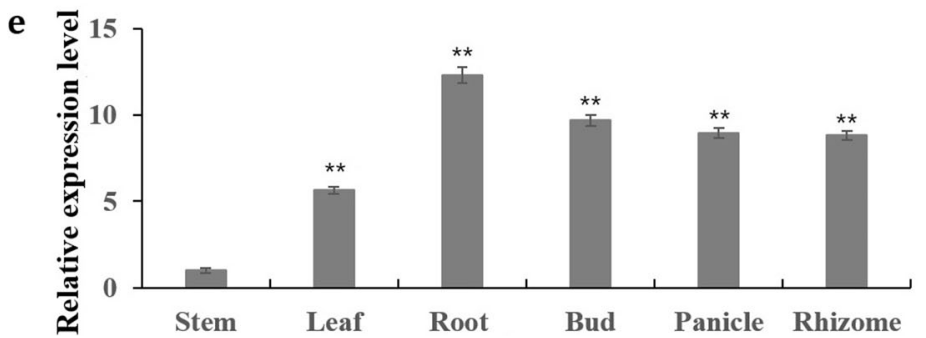

Fig. 1 The expression patterns of LCMYB2 under different treatments and its tissue-specific expression. a to $\mathbf{d}$ Expression of LCMYB2 in the seedlings of 8-week-old sheepgrass were treated with or without $300 \mathrm{mM}$ mannitol, $400 \mathrm{mmol} / \mathrm{L} \mathrm{NaCl}$, cold and $100 \mu \mathrm{mol} / \mathrm{L}$ ABA treatments for 0 , $1,3,8,12,24 \mathrm{~h}$ or $48 \mathrm{~h}$ after stress treatments. e LCMYB2 expression in stem, leaf, root, bud, panicle and rhizome of 1-year-old sheepgrass in flowering period. LCACTIN was used as a positive control for data normalization. Three independent replicates of measurements were performed for each time point, and the data are shown as the mean \pm standard deviation (SD) $(n=3)$

predict that $L c M Y B 2$ is mainly responsible for the osmotic stress response in roots, which may benefit plants under drought stress.

\section{Isolation and sequence analysis of the LCMYB2}

Putative full-length $L c M Y B 2$ was isolated from sheepgrass by Rapid-Amplification of cDNA Ends-PCR (RACE-PCR) and classical PCR based on the 454 high-throughput data (SRA065691; Additional file 2: S2). The length of LcMYB2 Open reading frame (ORF), region is $1092 \mathrm{bp}$, encoding 363 amino acids (GenBank: KY316376). The molecular mass of the putative protein is approximately $38.4 \mathrm{kDa}$, and its theoretical isoelectric point ( $\mathrm{pI}$ ) is 8.3 (predicted by DNAMAN 7.0). Multiple sequence alignment of LcMYB2 with its homologs shows that a conserved domain exists among these sequences (amino acids 101-171; Fig. 2a). Sequence similarity and phylogenetic analysis show that LcMYB2 forms a clade with BAK02871 (Hordeum vulgare), CDM81700 (Triticum aestivum) and EMT01615 (Aegilops tauschii) by a high nodal support values (Fig. 2b, c). However, the functions of these $L C M Y B 2$ homologs have not been reported thus far. The analysis of $L c M Y B 2$ biological function is of great significance for Leymus chinensis and closely related species Triticum aestivum and Aegilops tauschii homologs.

\section{Subcellular localization and transcription activity assay of LCMYB2}

To determine the subcellular localization of $L C M Y B 2$, the ORF of LcMYB2 (without the TGA stop codon) was fused to a GFP reporter gene under the control of the CaMV $35 \mathrm{~S}$ promoter (Fig. 3a). Recombinant CaMV35S::LcMYB2GFP and CaMV35S::GFP were transformed into Arabidopsis separately by the floral dip method. Confocal microscopy showed that the GFP protein was localized throughout the whole cell, whereas the LcMYB2-GFP fusion protein was present only in the nucleus (Fig. 3b), suggesting that LcMYB2 is a nuclear-localized protein. 


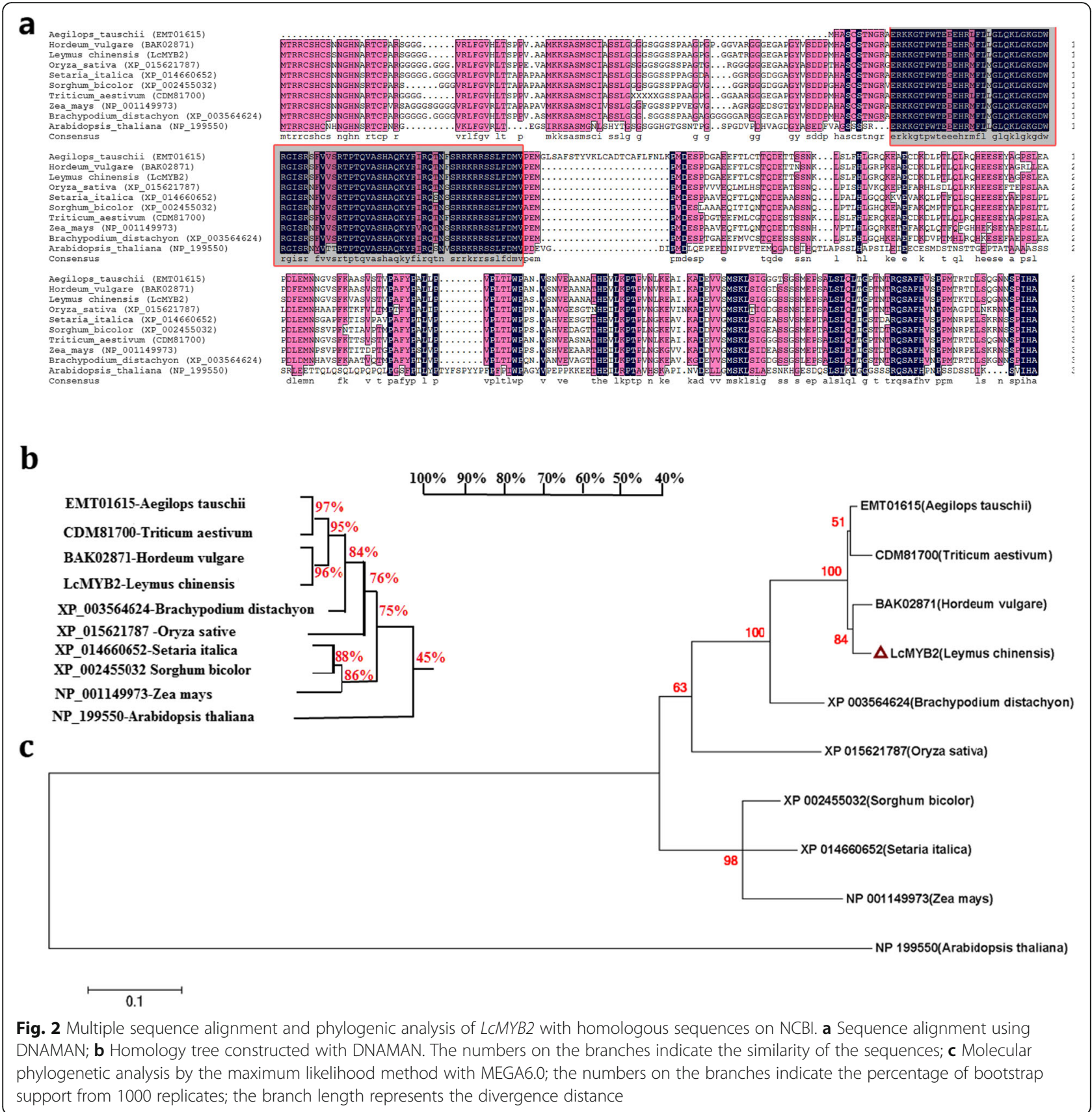

The transcriptional activation of $L c M Y B 2$ was tested using a yeast one-hybrid assay system. The LcMYB2 ORF was inserted at the 3 '-end of GAL-BD under the control of $\mathrm{P}_{\mathrm{ADH} 1}$ to form a BD-LCMYB2 fusion gene (Fig. 3c). The yeast strain AH109, harboring BDLcMYB2 or BD-WRKY15 (positive controls), grew normally on SD/-His-Trp medium, whereas AH109 harboring only $\mathrm{BD}$ (negative control) did not grow. In $\beta$ galactosidase activity assays on Whatman filter paper, blue signal appeared in the regions where BD-LcMYB2 or BD-WRKY15-containing yeast were growing (Fig. 3d).
Therefore, we suggest that $L c M Y B 2$ serves as a transcription activator and functions in the nucleus.

Performance of transgenic plants under osmotic stress, ABA treatment and natural drought treatment

First, we probed the biological functions of LcMYB2 at the seed germination stage under osmotic or $A B A$ treatment. Under normal conditions (MurashigeSkoog medium,MS), there were no significant differences between transgenic and wild-type seeds in germination rate, cotyledon greening rate or root length 


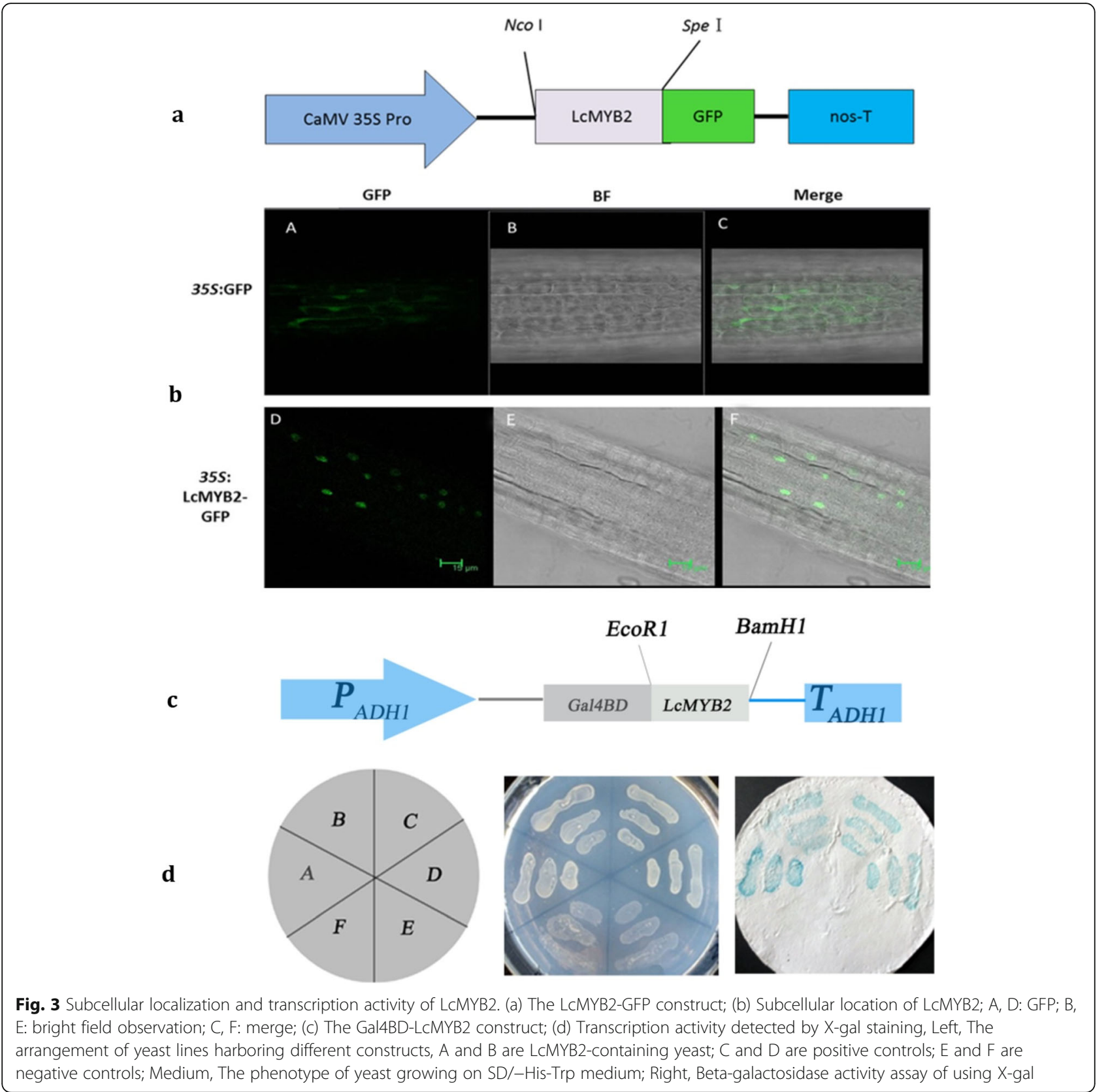

(Fig. 4a, d, g, c, f, i; Fig. 5a, d, g, h, i; Additional file 5: S5). Under treatment with $300 \mathrm{mmol} / \mathrm{L}$ mannitol, there were significant differences in germination rate $(p<0.01$; Fig. $4 \mathrm{~b}, \mathrm{c})$, and the cotyledon greening rate and root length had very significant differences $(p<0.001)$ between transgenic and wild-type seeds (Fig. 4e, f, h, i; Additional file 5: S5). Under treatment with $0.25 \mu \mathrm{mol} / \mathrm{L} \mathrm{ABA}$, the germination rate $(p<0.01)$, cotyledon greening rate $(p<$ $0.001)$ and root length $(\mathrm{p}<0.001)$ were significantly different between transgenic and wild-type seeds, and similar results were obtained with $0.5 \mu \mathrm{mol} / \mathrm{L}$ ABA treatment (Fig. 5b, c, e, f, g, h, i). Taken together, these data indicate that $L c M Y B 2$ can promote seed germination and root growth under osmotic stress and possibly via the ABA signaling pathway. In addition, the transgenic plants maintained green leaves longer under natural drought stress conditions and had a higher refresh rate after rewatering than did wild-type (Fig. 6).

To investigate the physiological responses of transgenic and wild-type $A$. thaliana under osmotic stress, we irrigated 4-week-old seedlings with $300 \mathrm{mmol} / \mathrm{L}$ mannitol. Two days later, the malondialdehyde (MDA), Superoxide dismutase (SOD), soluble sugars and proline contents were measured. The results showed that the 


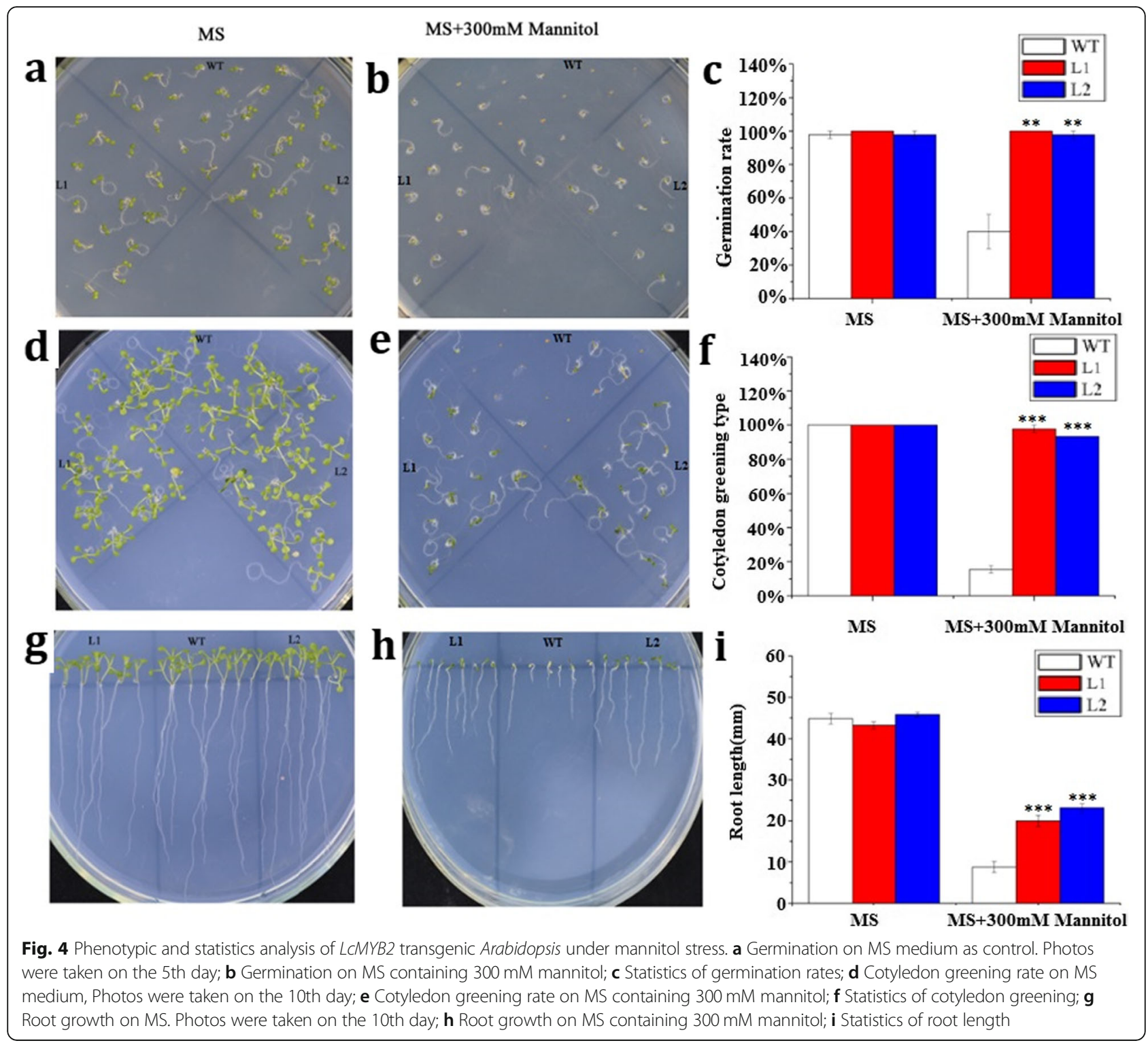

two transgenic lines overexpressing $L c M Y B 2$ accumulated greater amounts of SOD $(\mathrm{p}<0.01)$, soluble sugars $(p<0.05 / 0.01)$ and proline $(\mathrm{p}<0.001)$ than wild-type lines under $300 \mathrm{mmol} / \mathrm{L}$ mannitol treatment, whereas they had lower MDA content (Fig. 7a, b, c, d). The greater accumulation of proline and soluble sugars in the transgenic lines might provide extra protection to the cells under drought stress. The lower MDA and higher SOD content indicates that less damage occurred in the cells of transgenic plants. These results together suggest that $L c M Y B 2$ promotes osmotic stress resistance. The gene expression levels of AtDREB2A, AtP5CS1, and AtLEA14 were measured by Quantitative Real Time PCR (qPCR) on the 9th hour after treatment with $300 \mathrm{mmol} / \mathrm{L}$ mannitol. The expression levels of these genes were higher in transgenic plants than in wild-type plants both in the control check (CK) and in the treatment group (M9; Fig. 7e).

\section{CHIP analysis}

It has been shown that MYB proteins can recognize the motifs A/TAACCA and C/TAACG/TG [43]. Therefore, we analyzed the promoter sequences of AtLEA14, AtP5CS1, AtDREB2A and LCDREB2 using the sequences $\sim 1500-2000 \mathrm{bp}$ upstream of the predicted transcription start sites (TSSs), and several possible motifs were found in the putative promoter regions (Additional file 3: S3). We further confirmed our prediction with CHIP experiments, and the signals were detected in qPCR and universal PCR reactions with DNAs, released from proteins LICHIP, L2CHIP or LcCHIP, as templates. These results indicated that the LcMYB2 (or together with its 


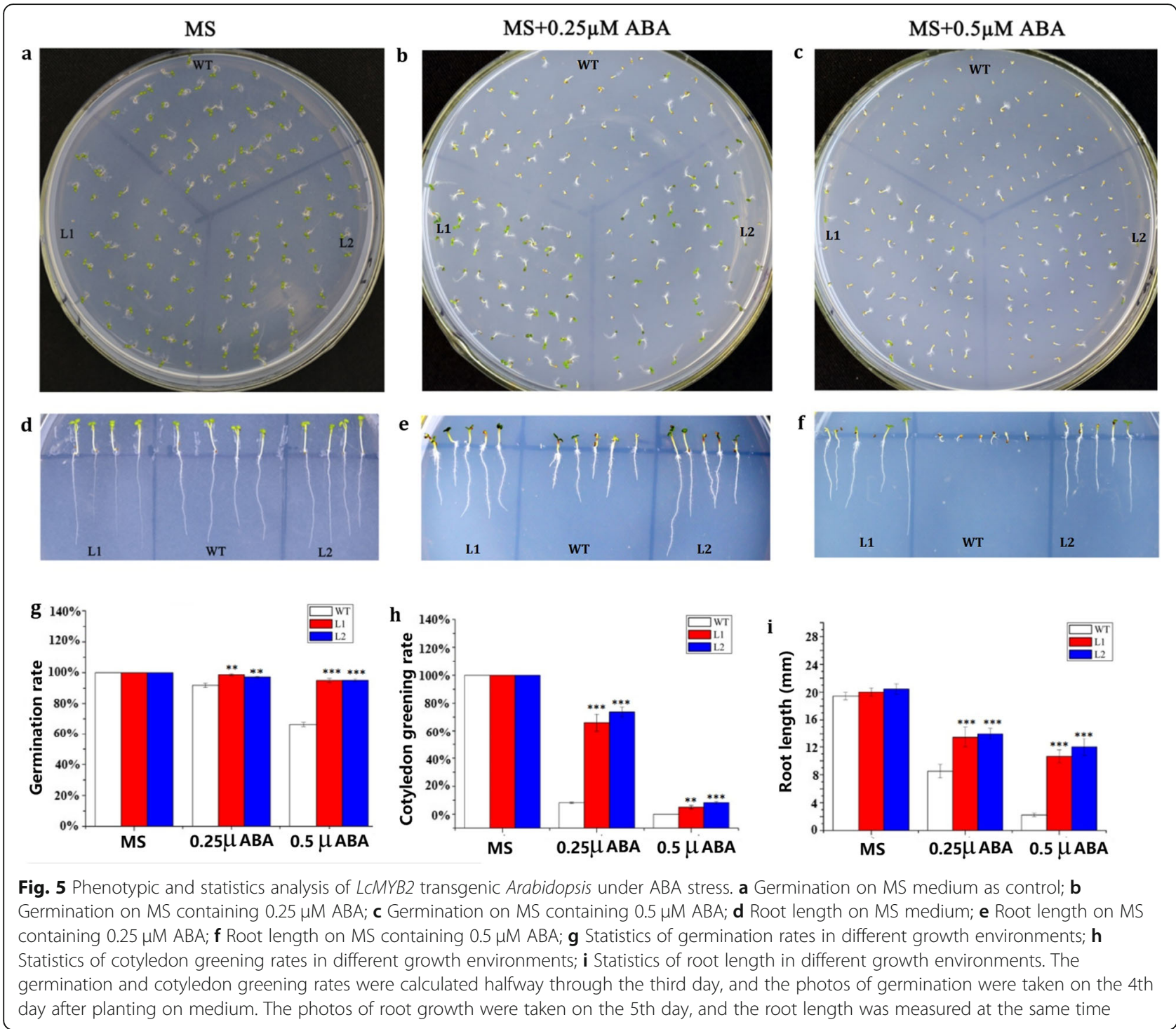

interaction proteins) regulates the expression of AtLEA14, AtP5CS1, AtDREB2A and LCDREB2 (Fig. 8).

\section{Discussion}

MYB and MYB-related transcription factors constitute a large family in plants and are involved in many biological processes, for example, secondary metabolism and responses to environmental factors [44-46]. Isolating and characterizing the functions of these genes provide a way to learn about plant-specific events at the transcriptional level. AtMYB2, a MYB-related protein, is induced by drought and by ABA; whereas BcMYB1 is rapidly and strongly induced by drought but only slightly by exogenous ABA, indicating that MYB proteins respond to environmental changes through both ABA-dependent and ABAindependent pathways [47-49]. LcMYB2 is induced to its maximal level at 1 hour after treatment with exogenous
$\mathrm{ABA}$ and 8 hours after treatment with exogenous mannitol (Fig. 1a, d). However, the extent of $L c M Y B 2$ induction by mannitol is greater than by ABA, suggesting that $L c M Y B 2$ functions mainly in an ABA-independent pathway.

When facing drought stress, plants always adopt avoidance or resistance strategies to mitigate the negative effects of the stress. Rooting deeply is one of the avoidance strategies. For example, the introduction of the DEEPER ROOTING 1 (DRO1) gene into a shallow-rooting rice cultivar increased the downward growth of roots, and the resulting transgenic lines had higher yields under drought conditions [3]. Our results demonstrate that LcMYB2 is induced by mannitol and promotes root elongation at the germination stage and during seedling growth under osmotic stress and ABA treatment (Fig. 4 and Fig. 5). Therefore, $L c M Y B 2$ has the potential to enhance plant root growth to avoid drought stress. 
a

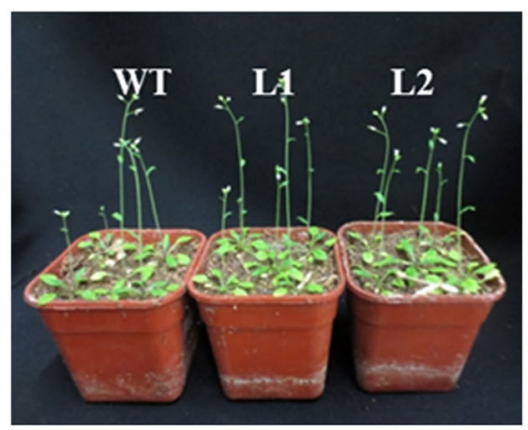

C

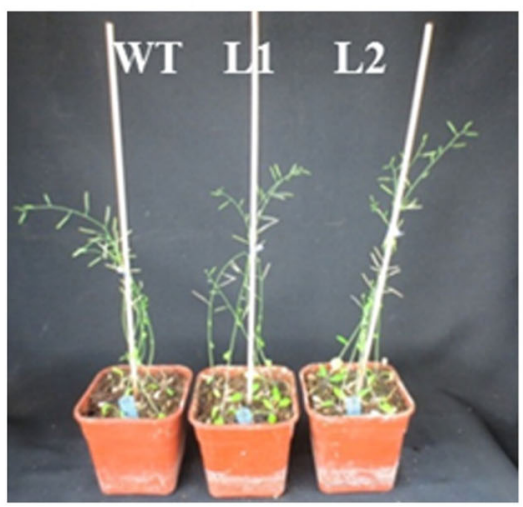

e b

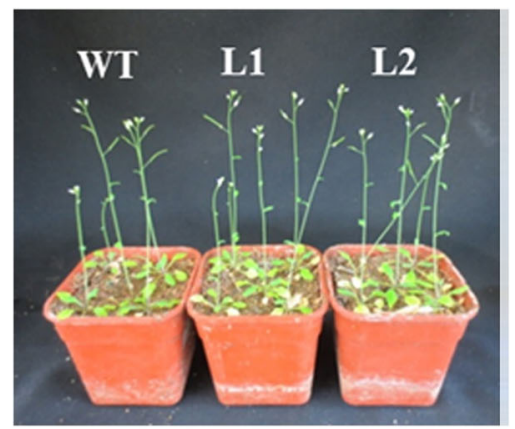

d

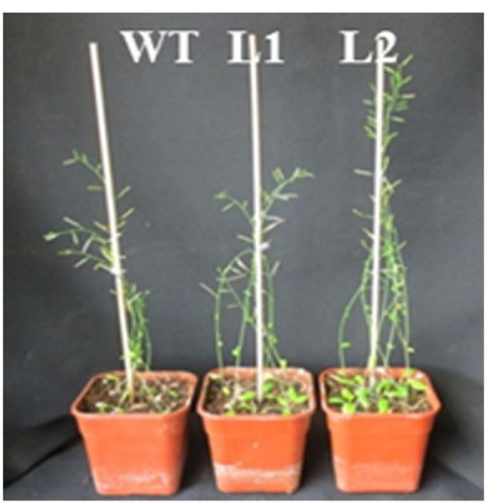

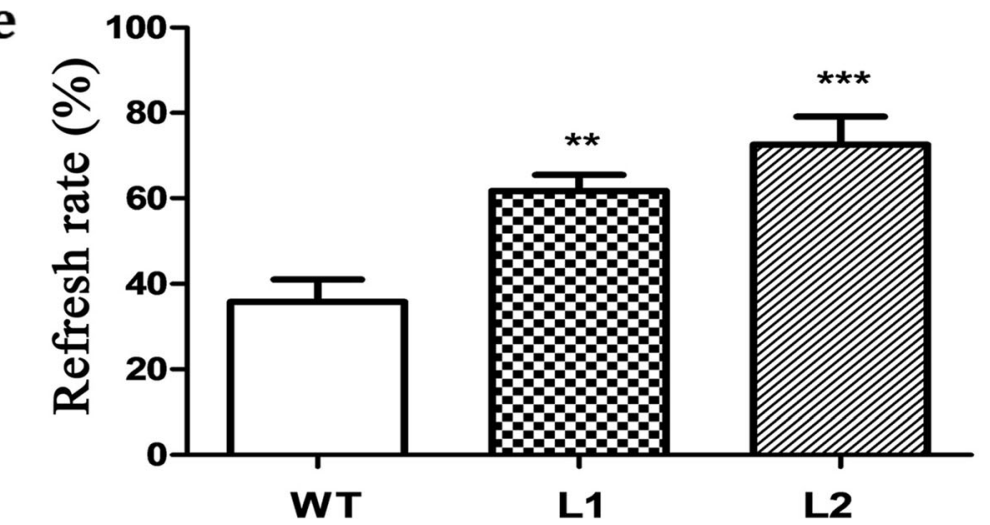

Fig. 6 Phenotypic and statistics analysis of LCMYB2 under natural drought. a Plants under natural drought stress for 21 days; $\mathbf{b}$ Plants under natural drought stress for 28 days; $\mathbf{c}$ Plants under natural drought stress for 42 days; $\mathbf{d}$ Plants 3 days after rewatering

Osmotic adjustment is usually thought to be one of the main mechanisms of resistance to drought or salt stress. Compatible osmolytes, such as proline, soluble sugars and LEA proteins, are often measured as critical physiological criteria to evaluate the tolerance of plants to abiotic stresses. Proline biosynthesis is catalyzed by P5CS1/2 and P5CR, and it is thought to protect subcellular structures and macromolecules under osmotic stress [50, 51]. Petunias overexpressing AtP5CS or OsP5CS accumulate more proline and appear to have drought tolerance [52]. In addition, soluble sugars, especially sucrose or trehalose, are correlated with the acquisition of desiccation tolerance and are thought to stabilize the membrane structure in dry environments $[53,54]$. LEA proteins, first found in cotton, were shown to be up-regulated by drought stress in many species and function as compatible solutes to maintain the cellular structure in severe dehydration conditions [54-56]. Overexpression of some LEA protein-encoding genes confers enhanced drought tolerance in transgenic plants $[57,58]$. Here, we found that LcMYB2 was induced by osmotic stress in sheepgrass (300mMmannitol); and $A$. thaliana overexpressing $L c M Y B 2$ accumulated more soluble sugars and free proline and expressed higher levels of AtLEA14, AtP5CS1 and AtDREB2A than wild-type A. thaliana seedlings under mannitol treatment (Fig. 7). In sheepgrass, many LEA protein-encoding genes and two P5CS-encoding genes were induced significantly by drought stress 35). Here, we demonstrate that LcMYB2 can bind to the promoter regions of AtLEA14 and 


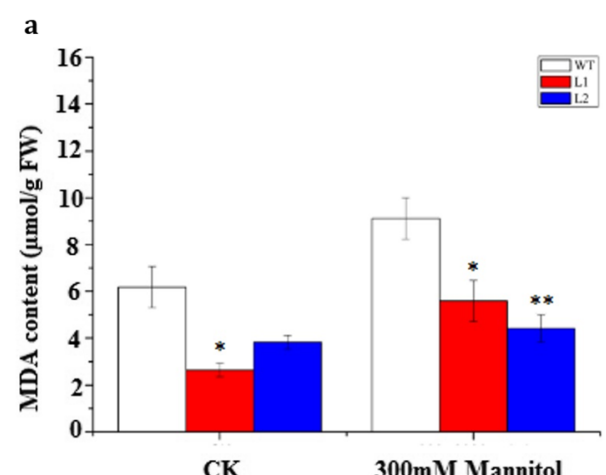

b
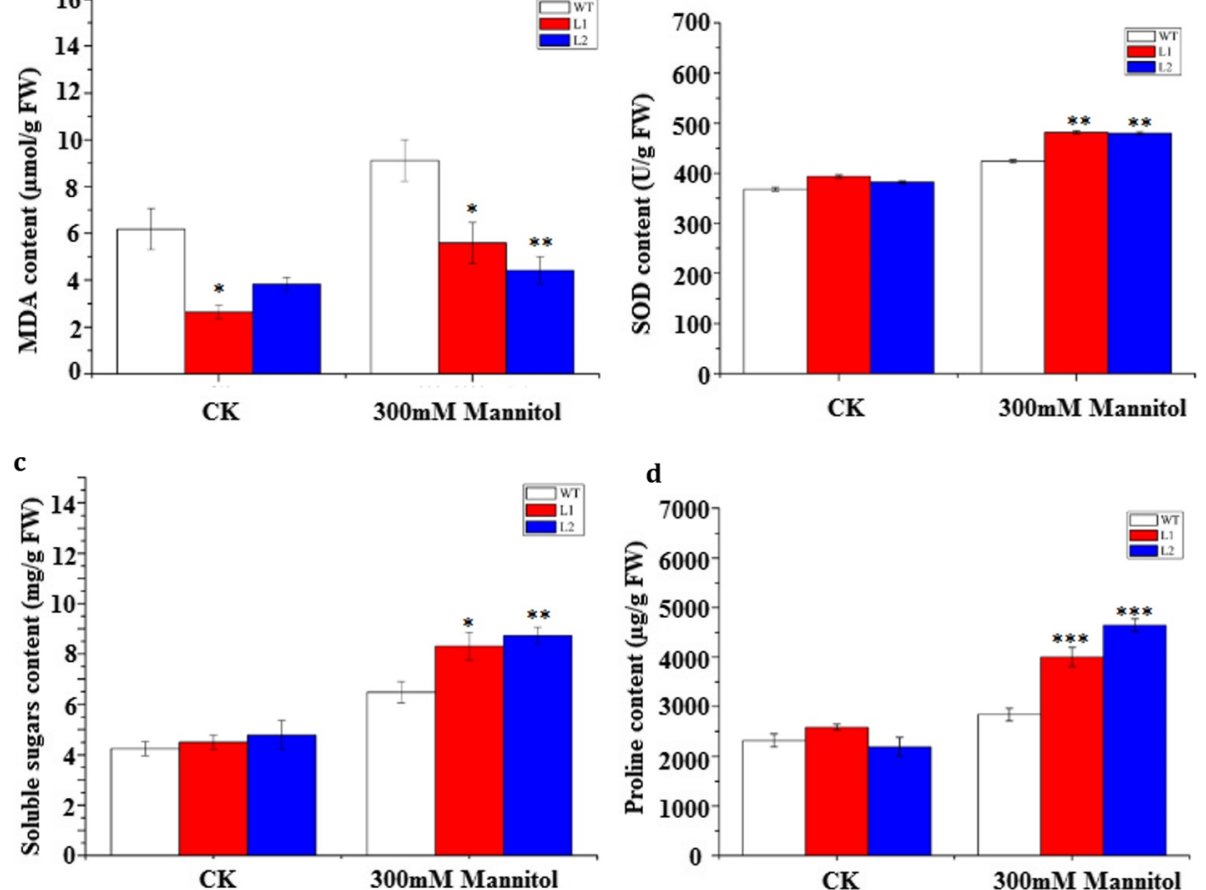

d

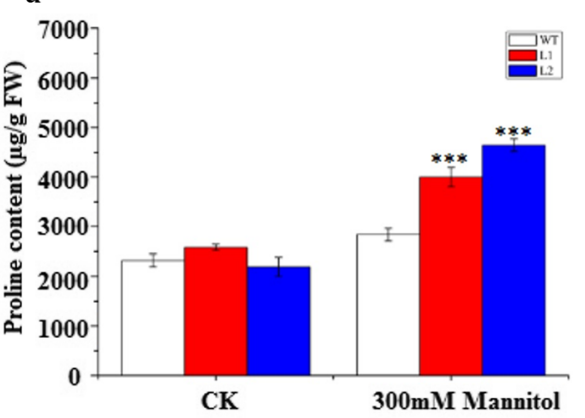

e

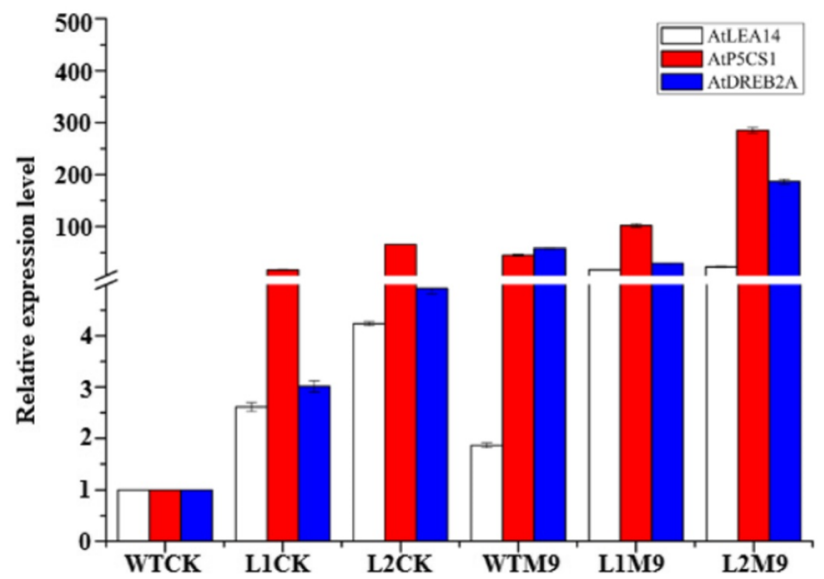

Fig. 7 LCMYB2 significantly increased the accumulation of proline under mannitol stress. a MDA content of wild-type and transgenic Arabidopsis thaliana under control conditions and osmotic stress; b SOD content of wild-type and transgenic Arabidopsis thaliana under control conditions and osmotic stress; c Soluble sugar content of wild-type and transgenic Arabidopsis thaliana under control conditions and osmotic stress; $\mathbf{d}$ Proline content of wild-type and transgenic Arabidopsis thaliana under control conditions and osmotic stress; e Changes in gene expression of AtDREB2A, AtP5CS1 and AtLEA14. Physiological indices were measured with the wild-type and transgenic Arabidopsis thaliana exposed to $300 \mathrm{mM}$ mannitol for 2 days

AtP5CS1 (Fig. 8a, b, e, f). Therefore, we suggest that $L c M Y B 2$ functions in sheepgrass by elevating the content of osmoprotectants.

DREB proteins have been extensively studied and have been shown to improve drought tolerance in transgenic plants. AtDREB2A and AtDREB2B are strongly induced by dehydration stress in roots and stems, and constitutive expression of AtDREB2A results in significant drought stress tolerance [21, 59].
In addition, OsDREB $2 B$ is markedly induced by various stresses, and overexpressing OsDREB2B in $A$. thaliana or rice increases the expression of DREB2A target genes and improves transgenic plant drought stress tolerance $[60,61]$. Previous studies have proposed that DREB proteins, such as DREB1 and DREB2, regulate low-temperature and droughtresponsive genes by binding to the DRE/CTR elements through ABA-independent pathway [62, 63]. 

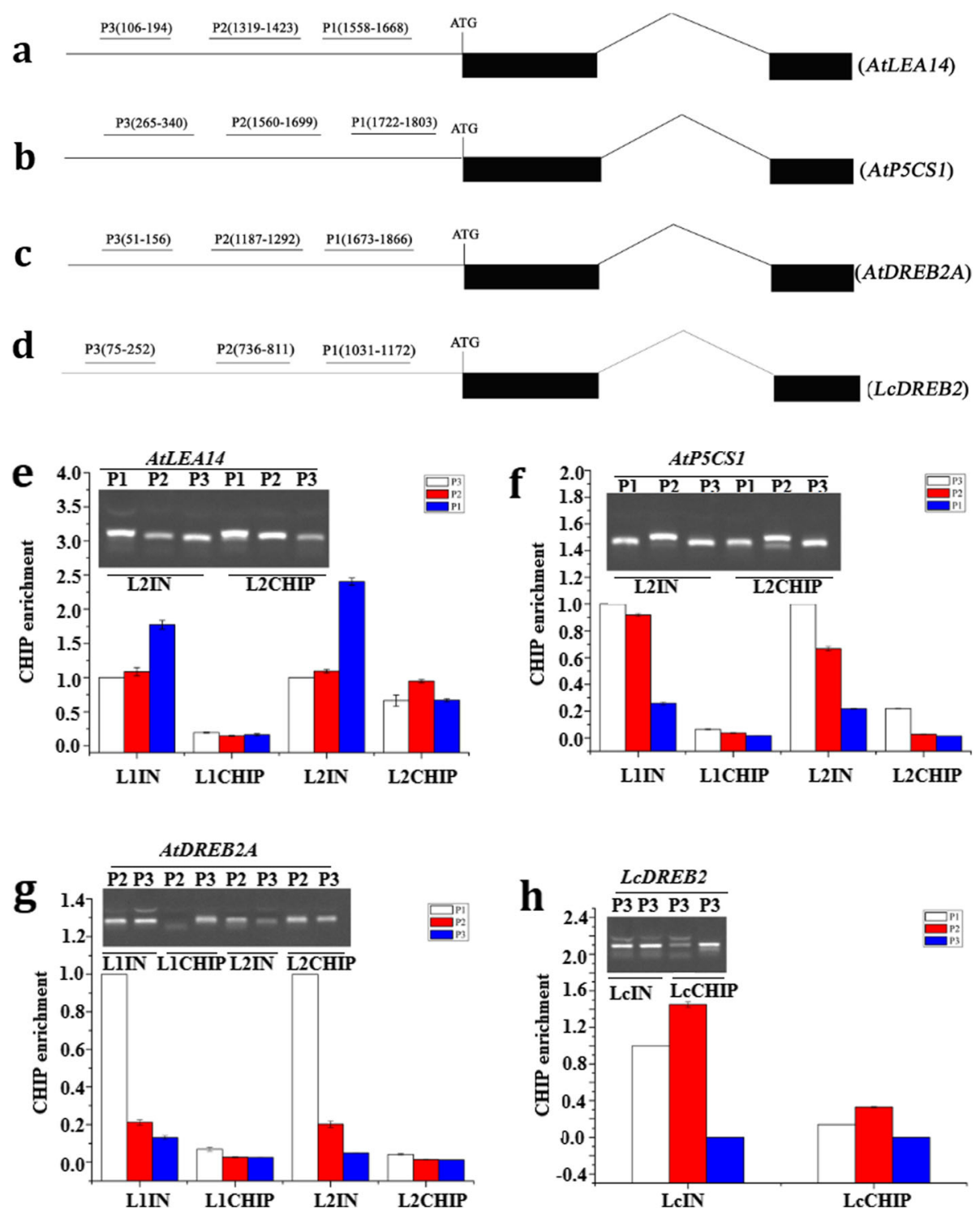

Fig. 8 LCMYB2 binds to the promoter regions of targets, as revealed by CHIP. L1IN, L2IN, LCIN were the plant total nucleoproteins of transgenic Arabidopsis line 1, line 2 and Leymus chinensis leaf, while, L1CHIP, L2CHIP and LCCHIP were proteins that pulled down by antibody of LCMYB2 (anti-LCMYB2) from L1IN, L2IN, LCIN respectively. The DNAs released from these proteins were collected for PCR and qPCR analyses. a Schematic of the AtLEA14 gene; $\mathbf{b}$ Schematic of the AtP5CS1 gene; $\mathbf{c}$ Schematic of the AtDREB2A gene; $\mathbf{d}$ Schematic of the LCDREB2 gene; e The binding of LCMYB2 to the promoter region of AtLEA14. f: The binding of LCMYB2 to the promoter region of AtP5CS1; $\mathbf{g}$ The binding of LCMYB2 to the promoter region of AtDREB2A; $\mathbf{h}$ The binding of LCMYB2 to the promoter region of LCDREB2

In sheepgrass, the highest transcript level of $L c D R E B 2 a$ occurs at the 12th hour under 20\% PEG6000 treatment [42], whereas LcMYB2 transcript accumulation reaches the highest point at $8 \mathrm{~h}$ after $300 \mathrm{Mm}$ mannitol treatment (Fig. 1a). Expression profile sequence analysis showed that both contig62249 (LCDREB2C/LCDREB2B/LCDREB2A) and contig41859 (LCMYB2) were up-regulated by drought stress and returned to basal levels after rewatering; however, the fold change of contig41859 was larger than that of contig62249 in response to drought stress (Additional file 1: S1). These results indicate that LcMYB2 is a possible transcription regulator upstream of $L c D R E B 2$. Therefore, we cloned the promoter sequence of $L C D R E B 2$ $(\sim 1500$ bp upstream of the predicted transcription start site, Additional file 2: S2) and assayed the binding of LcMYB2 protein to this promoter region using CHIP analysis. Universal PCR and qPCR enrichment of CHIP DNA revealed that LcMYB2 can bind to the promoter regions of both AtDREB2A and LcDREB2 (Fig. 8c, d, g, h). Therefore, we propose that LcMYB2 improves drought tolerance by activating $L C D R E B 2$ in sheepgrass. Also, we find that $L C M Y B 2$ can bind to the promoters of sheepgrass 
LCDREB2 and Arabidopsis AtDREB2A, maybe they all have MYB binding elements in their promoters, which shows that the mechanism of response to stress in plants is conservative. Otherwise, pearson correlation analysis with differentially expressed genes DEGs of sheepgrass transcriptome data under drought stress [35] to gain novel insights on the mechanism of LcMYB2 on drought stress, the pearson correlation analysis results showed that LcMYB2 expression level was perfectly positively correlated with the expressions of typical stress response genes of LcLEA, LCDREB2c, LcMYB39, Peroxidase 56 under drought stress in sheepgrass (Additional file 6: S6), which provided evidence for the analysis of LcMYB2 function under drought stress. The pearson correlation analysis results about the expression levels of LcMYB2 with LcLEA, LcDREB2c, LcMYB39 in sheepgrass were mutually underlying with the results of CHIP-PCR on LcMYB2 binding the corresponding promoter elements of AtLEA14, AtP5CS1, AtDREB2A and LcDREB2. This research integrates the RNA-seq further analysis, CHIP-PCR and universal PCR results, and provides the evidence for understanding the function of LcMYB2 under drought stress.

With the development of the sheepgrass industry (artificial cultivation, natural grassland improvement, and artificial grassland establishment), the drought resistance of sheepgrass during the seed germination and seedling establishment stages in water-deficient areas is critical for propagation and is necessary for reaping economic and ecological benefits. Therefore, LcMYB2 is an important candidate for improving plant drought stress tolerance through genetic engineering.

\section{Conclusions}

In conclusion, we showed that a drought and osmoticinducible transcription factor, LcMYB2, improves the drought and osmotic tolerance of plants by bingding the elements of promoters from the AtDREB2, AtLEA14, AtP5CS1 and LCDREB2 and regulating the transcription of drought-responsive genes to increase the accumulation of osmoprotectants (Fig. 9). These may be among the reasons underlying the tolerance of sheepgrass to drought-prone environments. Others, some the ciselements of stress response genes from the monocotyledons and dicotyledonous plants are conserved in evolution, they both can be bound by the same trans-factors.

\section{Methods}

\section{Plant materials and treatments}

Sheepgrass (National certified variety Zhongke 1 from Institute of Botany, the Chinese Academy of Sciences, Beijing, China) was used for this experiment. The sheepgrass seedlings were grown in a plastic pot containing nutrition soil (Pindstrup Bubstrate, Denmark) and vermiculite (2:1, v/v) in the greenhouse at $27 / 23^{\circ} \mathrm{C}, 16 \mathrm{~h}$ light $/ 8 \mathrm{~h}$ dark for 8

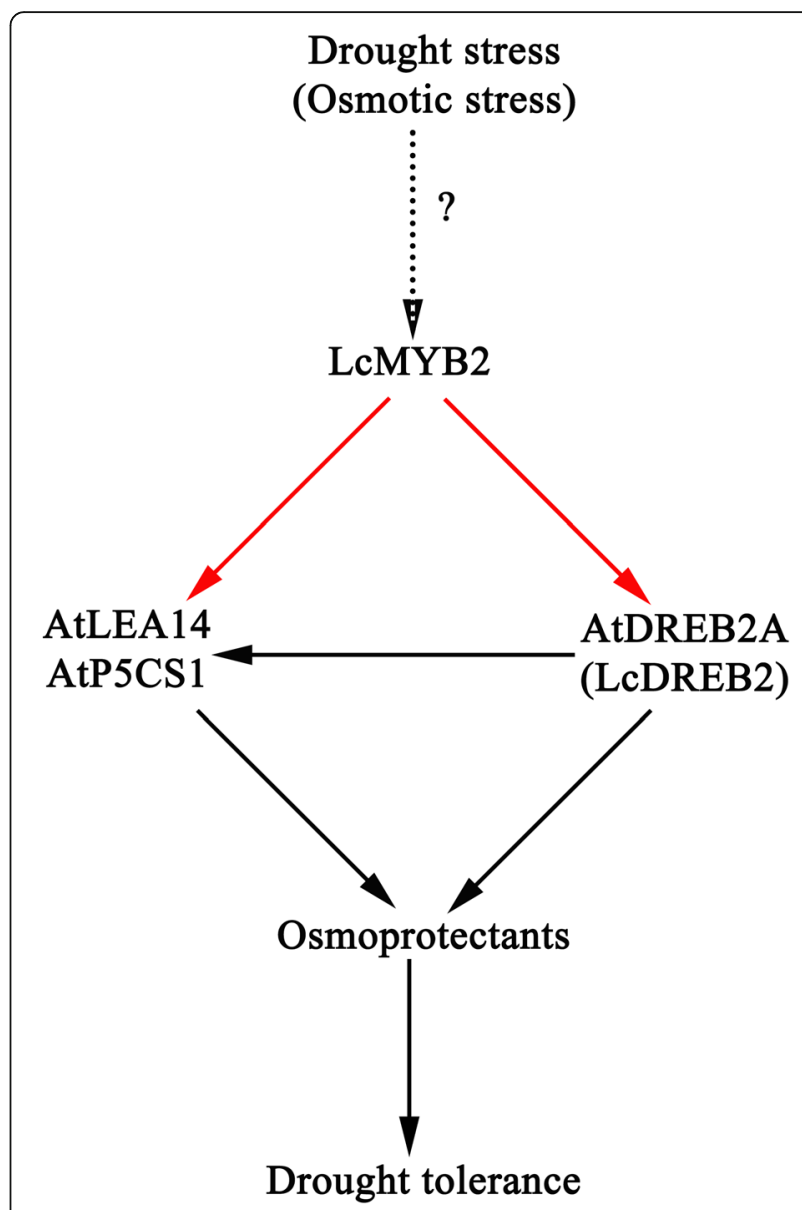

Fig. 9 A hypothetical model of LCMYB2 function in transgenic plants

weeks before treatments. Abiotic stresses were performed as follows: the plastic pots containing the seedlings were submerged in $100 \mu \mathrm{mol} / \mathrm{L}$ for $\mathrm{ABA}$ treatment, $300 \mathrm{mmol} / \mathrm{L}$ mannitol for osmotic stress and $400 \mathrm{mmol} / \mathrm{L} \mathrm{NaCl}$ for salt stress. Seedlings were transferred to a growth chamber at $4{ }^{\circ} \mathrm{C}$ for cold stress. The seedlings were sampled at $0,1,3$, 8,12 or $24 \mathrm{~h}$ after stress treatments, immediately frozen in liquid nitrogen and stored at $-80^{\circ} \mathrm{C}$ for RNA isolation. The abiotic stress experiments were excuted at least three times by different people to test the expression patterns of target genes. Stem, leaf, root, bud, panicle and rhizomes were also collected from 2-year-old sheepgrass seedlings for tissue-specific analysis.

Arabidopsis thaliana (A. thaliana; Columbia ecotype) seeds were surface-sterilized with $10 \% \mathrm{NaClO}$ for 10 min, and then washed 5 times with sterile water. The sterilized seeds were planted on MS solid media ( $\mathrm{pH}$ 5.8) for germination.

RNA isolation and expression pattern analysis of $L C M Y B 2$ Total RNA was extracted using Trizol reagent (TaKaRa, Dalian, China) according to the manufacturer's instructions. 
First-strand cDNA was synthesized using the PrimeScript ${ }^{\mathrm{m}}$ RT reagent Kit (TaKaRa, Dalian, China) according to the manufacturer's instructions. qRT-PCR was carried out in triplicate according to the SYBR PremixExTaq ${ }^{\text {Tix }}$ protocol (TaKaRa, Dalian, China) on a LightCycler480 Real-Time PCR System (Roche, Rotkreuz, Switzerland) with the following program: $95^{\circ} \mathrm{C}$ for $5 \mathrm{~s}$ and $68^{\circ} \mathrm{C}$ for $30 \mathrm{~s}$ for $45 \mathrm{cy}-$ cles. Tissue-specific expression of $L c M Y B 2$ was detected using semiquantitative PCR. All primers used in this research are listed in Additional file 4: S4.

\section{Amplification and sequence analysis of $L C M Y B 2$}

First-strand cDNA for amplification of the $5^{\prime}$ and $3^{\prime}$ ends of $L c M Y B 2$ was synthesized with SMARTer ${ }^{\text {TM }}$ RACE cDNA Amplification Kit (Clontech, Palo Alto, CA) according to the manufacturer's instructions. The genespecific primer (GSP-5'RACE), designed according to the 454 high-throughput sequencing results, and universal primers (UPM) were used to amplify the $5^{\prime}$ end of $L c M Y B 2$. The putative full-length sequence of $L c M Y B 2$ was amplified using gene-specific primers (LcMYB2-F/R) designed according to the sequence assembled from the 5 -RACE and 454 sequencing results. The national center for biotechnology information (NCBI) database was searched for homologs of LcMYB2 using the BLASTX program. Multiple sequence alignment was executed in DNAMAN software (version 7.0) using the selected amino acid sequences. The phylogenetic relationships among the homologs were inferred using the maximum likelihood method based on the JTT matrix-based model in MEGA software version $6.0[64,65]$.

\section{Subcellular localization and transcriptional activity assay of LCMYB2}

The ORF of $L c M Y B 2$ was ligated into pCAMBIA1302 to form the $L c M Y B 2-\mathrm{GFP}$ fusion protein. The recombinant plasmid was introduced into Agrobacterium tumefaciens EHA105 using a freeze-thaw method and further transformed into $A$. thaliana using the floral dip method [66]. Positive seedlings were selected on solid MS containing $50 \mu \mathrm{g} / \mathrm{L}$ hygromycin (Roche) and further confirmed by PCR. T3 seeds of the transgenic plants were germinated on MS, and the GFP fluorescence in the roots was observed under a laser confocal scanning microscope (Leica TCS SP5). To assess LcMYB2 transcription activity, the ORF was inserted downstream of GAL-BD in the pBridge vector to obtain pBD-LcMYB2. The recombinant vectors were introduced into the yeast strain AH109, and positive transformants were selected on SD (-Trp) medium and confirmed by PCR. $\beta$ galactosidase activity was assayed according to the Yeast Protocols Handbook (Clontech).

\section{Arabidopsis transformation}

To reveal the biological function of $L c M Y B 2$, the ORF was fused to the p3301-121 vector (modified from vector pCAMBIA3301 and pBI121, donated by the Shen lab) under the control of the CaMV $35 \mathrm{~S}$ promoter. The recombinant constructs were transformed into A. thaliana by Agrobacterium tumefaciens EHA105 using the floral dip method. Positive transgenic Arabidopsis seeds were screened on MS medium supplemented with $20 \mu \mathrm{g} / \mathrm{L}$ glufosinate ammonium and further confirmed by PCR using DNA extracted from the putative positive seedlings. T3 seeds were used for germination assays under different treatments.

\section{Drought stress tolerance analysis of transgenic seedlings}

To reveal the function of $L C M Y B 2$ at the germination stage, T3 seeds of transgenic and wild-type $A$. thaliana were planted on normal solid MS medium and solid MS medium supplemented mannitol $(300 \mathrm{~m} \mathrm{~mol} / \mathrm{L})$ or ABA $(0.25 \mu \mathrm{mol} / \mathrm{L}$ and $0.5 \mu \mathrm{mol} / \mathrm{L})$. The Petri dishes were placed in a growth chamber at $22^{\circ} \mathrm{C}$ with a $16 \mathrm{~h} / 8 \mathrm{~h}$, light/dark photoperiod. Plants were photographed, and the germination rate, cotyledon greening rate and root length were and measured. Osmotic and ABA stress tolerance experiments were repeated at least three times.

To test the role of $L c M Y B 2$ at the seedling stage under drought conditions, 4-day seedlings were transplanted into a pot containing vermiculite and turfy soil $(2: 1, \mathrm{v} / \mathrm{v})$ and grown in a growth chamber at $22^{\circ} \mathrm{C}$ with a $16 \mathrm{~h} / 8$ $\mathrm{h}$, light/dark photoperiod for 1 week with sufficient water, then started to natural drought stress without water for the following 42 days. During the drought process, the soil water content was monitored every day in each pot. On the 42nd day, the seedlings were irrigated again, and survival rates were statistically analyzed after 3 days. There are 60 seedlings for drought stress experiment in each line (WT, L1, L2), respectively.

\section{Measurement of lipid peroxidation and of proline and soluble sugar content}

Four-week-old transgenic and WT A. thaliana seedlings were irrigated with $300 \mathrm{mmol} / \mathrm{L}$ mannitol. The leaves were sampled at $0 \mathrm{~h}$ and $9 \mathrm{~h}$ after treatment for gene expression analysis. Two days later, the leaves of transgenic and wild-type lines were harvested for physiological measurements. The level of MDAwas determined by a revised method described by Kramer et al. [67]. SOD content was measured with the nitro-blue tetrazolium (NBT) reduction method as previously described [68]. The contents of proline and soluble sugars were determined according to the protocols previously described by Shan et al. [69] and Bailey [70], respectively. Three replicates were carried out for each assay, and the variability was indicated with the standard error (SE). 


\section{Chromatin immunoprecipitation assays}

Four-week-old seedlings of sheepgrass were treated with $300 \mathrm{mmol} / \mathrm{L}$ mannitol for $8 \mathrm{~h}$ and $24 \mathrm{~h}$ to induce the expression of $L c M Y B 2$, after which time, the samples were harvested. Six-week-old seedlings of $A$. thaliana overexpressing LcMYB2 (L1: line 1, L2: line 2) were tested. All samples were fixed with formaldehyde for CHIP analysis. Antibodies against LcMYB2 were prepared by Beijing Protein Innovation Co., Ltd. The EpiQuik Plant ChIP kit (Epigentek, Brooklyn, NY) was used for CHIPanalysis. CHIP DNA was detected with universal PCR ( 40 cycles of $\left.95^{\circ} \mathrm{C}, 30 \mathrm{~S} ; 68^{\circ} \mathrm{C}, 30 \mathrm{~S}\right)$ and qPCR $\left(45\right.$ cycles of $95^{\circ} \mathrm{C}$, $5 \mathrm{~S} ; 68^{\circ} \mathrm{C}, 30 \mathrm{~S}$ ). The method of comparing $\mathrm{Ct}$ values was adopted to analyze the qPCR CHIP efficiency.

\section{Statistical analysis}

Analysis of variance (ANOVA) and t-test were used to compare the differences between samples. ${ }^{* * * *}$ indicates $p$-values $<0.001$, ** indicates $\mathrm{p}$-values $<0.01)$ and * indicates p-values $<0.05$.

\section{Supplementary information}

Supplementary information accompanies this paper at https://doi.org/10. 1186/s12870-019-2159-2

Additional file 1. S1 MYB-related transcription factor with unknown function.

Additional file 2. S2. Amplification of full-length LCMYB2 and Amplification of LCDREB2 promoter sequence.

Additional file 3. S3 Promoter sequence used in CHIP experiment and Possible MYB recognition site.

Additional file 4. S4. Primers used in this research.

Additional file 5. S5. The root growth experiment.

Additional file 6. S6. Pearson correlation analysis between LCMYB2 and other genes.

\section{Abbreviations}

ABA: Abscisic acid; AP2/ERF: APETUAP2/Ethylene-Responsive-Element Binding Protein; bZIP: Basic Leucine Zipper; CHIP: Chromatin immunoprecipitation; DREB: Dehydration Responsive Element Binding Protein; LCMYB2: Leymus chinensis MYB DNA-binding domain protein 2; LEA: Late-embryogenesisabundant protein; MS: Murashige-Skoog medium; MYB: MYB DNA-binding domain protein 2; NAC: NAM, ATAF and CUC transcription factor; NCBI: The national center for biotechnology information; ORF: Open reading frame; P5CS1: $\triangle 1$-Pyrroline-5-carboxylate synthetas; PP2Cs: Plant protein phosphatases; qPCR: Quantitative Real Time PCR; RACE-PCR: RapidAmplification of cDNA Ends-PCR

\section{Acknowledgements}

We thank Dr. Xiaobing Dong supplied much contribution in materials collection and management.

\section{Authors' contributions}

GL and LC conceived and designed the experiments. SH performed most of the experiments. PZ, XG and LC made substantial contributions to the data analysis and the manuscript writing. GL gave the final approval the manuscript. JJ, WY, ZL, SC, XL and DQ were involved in performing the experiments; all authors read and approved the final manuscript.

\section{Funding}

This work was supported by the National Basic Research Program of China ("973" program, 2014CB138704), the Project of Science and Technology Service Network Initiative of the Chinese Academy of Sciences (STS, KFJ-EWSTS-119), Kulun Banner Science and Technology Poverty Alleviation Project of Chinese Academy of Sciences, and the Science and Technology Major Project of Inner Mongolia Autonomous Region of China. The funders had no role in the design of the study and collection, analysis, and interpretation of data and in writing the manuscript, but just provide the financial support.

\section{Availability of data and materials}

Not applicable.

Ethics approval and consent to participate

Not applicable.

Consent for publication

Not applicable.

\section{Competing interests}

The authors declare that they have no competing interests.

\section{Author details}

'Key Laboratory of Plant Resources, Institute of Botany, The Chinese

Academy of Sciences, Beijing, China. ${ }^{2}$ College of Management Science And Engineering, Hebei University of Economics and Business, Shijiazhuang, China. ${ }^{3}$ Institute of Millet Crops, Hebei Academy of Agricultural \& Forestry Sciences, Shijiazhuang, China. ${ }^{4}$ Branch of Animal Husbandry and Veterinary of Heilongjiang Academy of Agricultural Sciences, Qiqihar, China.

${ }^{5}$ Agro-Biological Gene Research Center, Guangdong Academy of Agricultural Sciences, Guangzhou, China.

Received: 20 June 2019 Accepted: 25 November 2019

Published online: 18 December 2019

\section{References}

1. Baskin CC, Baskin JM. Seeds: ecology, biogeography, and evolution of dormancy and germination 2nd ed.[M]:AP; 2014.

2. Mickelbart MV, Hasegawa PM, Bailey-Serres J. Genetic mechanisms of abiotic stress tolerance that translate to crop yield stability. Nat Rev Genet. 2015;16: 237-51.

3. Uga Y, Sugimoto K, Ogawa S, Rane J, Ishitani M, Hara N, et al. Control of root system architecture by DEEPER ROOTING 1 increases rice yield under drought conditions. Nat Genet. 2013:45:1097.

4. Chen THH, Murata N. Glycinebetaine: an effective protectant against abiotic stress in plants. Trends Plant Sci. 2008;13:499-505.

5. Kollist $H$, Nuhkat $M$, Roelfsema MRG. Closing gaps: linking elements that control stomatal movement. New Phytol. 2014;203:44-62.

6. Valliyodan B, Nguyen HT. Understanding regulatory networks and engineering for enhanced drought tolerance in plants. Curr Opin Plant Biol. 2006:9:189-95

7. Valluru R, Van den Ende W. Plant fructans in stress environments: emerging concepts and future prospects. J Exp Bot. 2008:59:2905-16.

8. Zhu JK. Salt and drought stress signal transduction in plants. Annu Rev Plant Biol. 2002:53:247-73.

9. Zhu JK. Abiotic stress signaling and responses in plants. Cell. 2016;167: 313-24.

10. Geiger D, Scherzer S, Mumm P, Stange A, Marten I, Bauer H, et al. Activity of guard cell anion channel SLAC1 is controlled by drought-stress signaling kinase-phosphatase pair. Proc Natl Acad Sci U S A. 2009;106:21425-30.

11. Savoure A, Hua XJ, Bertauche N, VanMontagu M, Verbruggen N. Abscisic acid-independent and abscisic acid-dependent regulation of proline biosynthesis following cold and osmotic stresses in Arabidopsis thaliana. Mol Gen Genet. 1997:254:104-9.

12. Strizhov N, Abraham E, Okresz L, Blickling S, Zilberstein A, Schell J, et al. Differential expression of two P5CS genes controlling proline accumulation during salt-stress requires $A B A$ and is regulated by $A B A 1, A B \mid 1$ and $A X R 2$ in Arabidopsis. Plant J. 1997:12:557-69.

13. Urano K, Maruyama K, Ogata Y, Morishita Y, Takeda M, Sakurai N, et al Characterization of the ABA-regulated global responses to dehydration in Arabidopsis by metabolomics. Plant J. 2009;57:1065-78. 
14. Ma Y, Szostkiewicz I, Korte A, Moes D, Yang Y, Christmann A, et al. Regulators of PP2C phosphatase activity function as Abscisic acid sensors. Science. 2009;324:1064-8.

15. Miyakawa T, Fujita Y, Yamaguchi-Shinozaki K, Tanokura M. Structure and function of abscisic acid receptors. Trends Plant Sci. 2013;18:259-66.

16. Miyazono K, Miyakawa T, Sawano Y, Kubota K, Kang HJ, Asano A, et al. Structural basis of abscisic acid signalling. Nature. 2009;462:609-U679.

17. Santiago J, Dupeux F, Round A, Antoni R, Park SY, Jamin M, et al. The abscisic acid receptor PYR1 in complex with abscisic acid. Nature. 2009;462: $665-U 143$

18. Fujii H, Chinnusamy V, Rodrigues A, Rubio S, Antoni R, Park SY, et al. In vitro reconstitution of an abscisic acid signalling pathway. Nature. 2009;462:660-U138.

19. Raghavendra AS, Gonugunta VK, Christmann A, Grill E. ABA perception and signalling. Trends Plant Sci. 2010;15:395-401

20. Fujita Y, Fujita M, Shinozaki K, Yamaguchi-Shinozaki K. ABA-mediated transcriptional regulation in response to osmotic stress in plants. J Plant Res. 2011;124:509-25.

21. Sakuma Y, Maruyama K, Osakabe Y, Qin F, Seki M, Shinozaki K, et al. Functional analysis of an Arabidopsis transcription factor, DREB2A, involved in drought-responsive gene expression. Plant Cell. 2006;18:1292-309.

22. Xu ZS, Chen M, Li LC, Ma YZ. Functions and application of the AP2/ERF transcription factor family in crop improvement. J Integr Plant Biol. 2011;53: 570-85.

23. Dubos C, Stracke R, Grotewold E, Weisshaar B, Martin C, Lepiniec L. MYB transcription factors in Arabidopsis. Trends Plant Sci. 2010;15:573-81.

24. Cominelli E, Galbiati M, Vavasseur A, Conti L, Sala T, Vuylsteke M, et al. A guard-cell-specific MYB transcription factor regulates stomatal movements and plant drought tolerance. Curr Biol. 2005;15:1196-200.

25. Liang YK, Dubos C, Dodd IC, Holroyd GH, Hetherington AM, Campbell MM AtMYB61, an R2R3-MYB transcription factor controlling stomatal aperture in Arabidopsis thaliana. Curr Biol. 2005;15:1201-6.

26. Seo PJ, Xiang FN, Qiao M, Park JY, Lee YN, Kim SG, et al. The MYB96 transcription factor mediates Abscisic acid signaling during drought stress response in Arabidopsis. Plant Physiol. 2009;151:275-89.

27. Jung C, Seo JS, Han SW, Koo YJ, Kim CH, Song Sl, et al. Overexpression of AtMYB44 enhances stomatal closure to confer abiotic stress tolerance in transgenic Arabidopsis. Plant Physiol. 2008;146:623-35.

28. Qin YX, Wang MC, Tian YC, He WX, Han L, Xia GM. Over-expression of TaMYB33 encoding a novel wheat MYB transcription factor increases salt and drought tolerance in Arabidopsis. Mol Biol Rep. 2012;39:7183-92.

29. Shin D, Moon SJ, Han S, Kim BG, Park SR, Lee SK, et al. Expression of StMYB1R-1, a novel potato single MYB-like domain transcription factor, increases drought Tolerance. Plant Physiol. 2011;155:421-32.

30. Zhang ZY, Liu X, Wang XD, Zhou MP, Zhou XY, Ye XG, et al. An R2R3 MYB transcription factor in wheat, TaPIMP1, mediates host resistance to Bipolaris sorokiniana and drought stresses through regulation of defense- and stressrelated genes. New Phytol. 2012;196:1155-70.

31. Wang XL, Wang HW, Liu SX, Ferjani A, Li JS, Yan JB, et al. Genetic variation in ZmVPP1 contributes to drought tolerance in maize seedlings. Nat Genet. 2016;48:1233-41.

32. Chen $S Y$, Huang $X$, Yan XQ, Liang Y, Wang YZ, Li XF, et al. Transcriptome analysis in Sheepgrass (Leymus chinensis): a dominant perennial grass of the Eurasian steppe. PLoS One. 2013:8:11.

33. Zhai JF, Dong YY, Sun YP, Wang Q, Wang N, Wang FW, et al. Discovery and analysis of MicroRNAs in Leymus chinensis under saline-alkali and drought stress using high-throughput sequencing. PLOS One. 2014;9(11):e105417.

34. Sun YP, Wang FW, Wang N, Dong YY, Liu Q, Zhao L, et al. Transcriptome exploration in Leymus chinensis under saline-alkaline treatment using 454 pyrosequencing. PLoS One. 2013;8(1):e53632.

35. Zhao PC, Liu PP, Yuan GX, Jia JT, Li XX, Qi DM, et al. New insights on drought stress response by global investigation of gene expression changes in Sheepgrass (Leymus chinensis). Front Plant Sci. 2016;7:954.

36. Cheng LQ, Li XX, Huang X, Ma T, Liang Y, Ma XY, et al. Overexpression of sheepgrass R1-MYB transcription factor LCMYB1 confers salt tolerance in transgenic Arabidopsis. Plant Physiol Biochem. 2013;70:252-60.

37. Gao Q, Li XX, Jia JT, Zhao PC, Liu PP, Liu ZJ, et al. Overexpression of a novel cold-responsive transcript factor LCFIN1 from sheepgrass enhances tolerance to low temperature stress in transgenic plants. Plant Biotechnol J. 2016;14:861-74

38. Yu CQ, Gong P, Yin YY. China's water crisis needs more than words. Nature. 2011;470:307.
39. Li XX, Gao Q, Liang Y, Ma T, Cheng LQ, Qi DM, et al. A novel salt-induced gene from sheepgrass, LCSAIN2, enhances salt tolerance in transgenic Arabidopsis. Plant Physiol Biochem. 2013;64:52-9.

40. Li XX, Hou SL, Gao Q, Zhao PC, Chen SY, Qi DM, et al. LCSAIN1, a novel saltinduced gene from SheepGrass, confers salt stress tolerance in transgenic Arabidopsis and Rice. Plant Cell Physiol. 2013;54:1172-85.

41. Peng XJ, Ma XY, Fan WH, Su M, Cheng LQ, Alam I, et al. Improved drought and salt tolerance of Arabidopsis thaliana by transgenic expression of a novel DREB gene from Leymus chinensis. Plant Cell Rep. 2011;30:1493-502.

42. Peng XJ, Zhang LX, Zhang LX, Liu ZJ, Cheng LQ, Yang Y, et al. The transcriptional factor LCDREB2 cooperates with LCSAMDC2 to contribute to salt tolerance in Leymus chinensis. Plant Cell Tiss Org Cult. 2013;113:245-56.

43. Abe H, Urao T, Ito T, Seki M, Shinozaki K, Yamaguchi-Shinozaki K. Arabidopsis AtMYC2 (bHLH) and AtMYB2 (MYB) function as transcriptional activators in abscisic acid signaling. Plant Cell. 2003;15:63-78.

44. Gatica-Arias A, Farag MA, Stanke M, Matousek J, Wessjohann L, Weber G. Flavonoid production in transgenic hop (Humulus lupulus L.) altered by PAP1/MYB75 from Arabidopsis thaliana L. Plant Cell Rep. 2012;31:111-9.

45. Lotkowska ME, Tohge T, Fernie AR, Xue GP, Balazadeh S, Mueller-Roeber B. The Arabidopsis transcription factor MYB112 promotes anthocyanin formation during salinity and under high light stress. Plant Physiol. 2015;169: 1862-80.

46. Ren LJ, Hu ZL, Li YL, Zhang B, Zhang YJ, Tu Y, et al. Heterologous expression of BoPAP1 in tomato induces stamen specific anthocyanin accumulation and enhances tolerance to a long-term low temperature stress. J Plant Growth Regul. 2014;33:757-68.

47. Chen BJ, Wang Y, Hu YL, Wu Q, Lin ZP. Cloning and characterization of a drought-inducible MYB gene from Boea crassifolia. Plant Sci. 2005;168: 493-500.

48. Urao T, Noji M, YamaguchiShinozaki K, Shinozaki K. A transcriptional activation domain of ATMYB2, a drought-inducible Arabidopsis Myb-related protein. Plant J. 1996:10:1145-8.

49. Urao T, Yamaguchishinozaki K, Urao S, Shinozaki K. An Arabidopsis Myb homolog is induced by dehydration stress and its gene-product binds to the conserved Myb recognition sequence. Plant Cell. 1993;5:1529-39.

50. Kishor PBK, Sangam S, Amrutha RN, Laxmi PS, Naidu KR, Rao KRSS, et al. Regulation of proline biosynthesis, degradation, uptake and transport in higher plants: its implications in plant growth and abiotic stress tolerance. Curr Sci. 2005;88:424-38.

51. Szabados L, Savoure A. Proline: a multifunctional amino acid. Trends Plant Sci. 2010;15:89-97.

52. Yamada M, Morishita H, Urano K, Shiozaki N, Yamaguchi-Shinozaki K, Shinozaki K, et al. Effects of free proline accumulation in petunias under drought stress. J Exp Bot. 2005;56:1975-81.

53. Crowe JH, Hoekstra FA, Crowe LM. An hydrobiosis. Annu Rev Physiol. 1992; 54:579-99.

54. Ingram J, Bartels D. The molecular basis of dehydration tolerance in plants. Annu Rev Plant Physiol Plant Mol Biol. 1996;47:377-403.

55. Dure L, Greenway SC, Galau GA. Developmental biochemistry of cottonseed embryogenesis and germination-changing messenger ribonucleic-acid populations as shown by invitro and invivo protein-synthesis. Biochemistry. 1981;20(14):4162-8.

56. Xu DP, Duan XL, Wang BY, Hong BM, Ho THD, Wu R. Expression of a late embryogenesis abundant protein gene, HVA1, from barley confers tolerance to water deficit and salt stress in transgenic rice. Plant Physiol. 1996:110: 249-57.

57. Xiao BZ, Huang YM, Tang $N$, Xiong LZ. Over-expression of a LEA gene in rice improves drought resistance under the field conditions. Theor Appl Genet. 2007;115:35-46

58. Goyal K, Walton $L$, Tunnacliffe A. LEA proteins prevent protein aggregation due to water stress. Biochem J. 2005;388:151-7.

59. Nakashima K, Shinwari ZK, Sakuma Y, Seki M, Miura S, Shinozaki K, et al. Organization and expression of two Arabidopsis DREB2 genes encoding DRE-binding proteins involved in dehydration- and high-salinity-responsive gene expression. Plant Mol Biol. 2000;42:657-65.

60. Chen JQ, Meng XP, Zhang Y, Xia M, Wang XP. Over-expression of OsDREB genes lead to enhanced drought tolerance in rice. Biotechnol Lett. 2008;30:2191-8.

61. Matsukura S, Mizoi J, Yoshida T, Todaka D, Ito Y, Maruyama K, et al. Comprehensive analysis of rice DREB2-type genes that encode transcription factors involved in the expression of abiotic stress-responsive genes. Mol Genet Genomics. 2010;283:185-96. 
62. Liu Q, Kasuga M, Sakuma Y, Abe H, Miura S, Yamaguchi-Shinozaki K, et al. Two transcription factors, DREB1 and DREB2, with an EREBP/AP2 DNA binding domain separate two cellular signal transduction pathways in drought- and low-temperature-responsive gene expression, respectively, in Arabidopsis. Plant Cell. 1998;10:1391-406.

63. Stockinger EJ, Gilmour SJ, Thomashow MF. Arabidopsis thaliana CBF1 encodes an AP2 domain-containing transcriptional activator that binds to the C-repeat/DRE, a cis-acting DNA regulatory element that stimulates transcription in response to low temperature and water deficit. Proc Natl Acad Sci U S A. 1997;94:1035-40.

64. Jones DT, Taylor WR, Thornton JM. The rapid generation of mutation data matrices from protein sequences. Comput Appl Biosci. 1992;8:275-82.

65. Tamura K, Stecher G, Peterson D, Filipski A, Kumar S. MEGA6: molecular evolutionary genetics analysis version 6.0. Mol Biol Evol. 2013;30:2725-9.

66. Clough SJ, Bent AF. Floral dip: a simplified method for agrobacteriummediated transformation of Arabidopsis thaliana. Plant J. 1998;16:735-43.

67. Kramer GF, Norman HA, Krizek DT, Mirecki RM. Influence of Uv-B radiation on polyamines, lipid-peroxidation and membrane-lipids in cucumber. Phytochemistry. 1991;30:2101-8.

68. Durak I, Yurtarslanl Z, Canbolat O, Akyol O. A methodological approach to superoxide-dismutase (sod) activity assay based on inhibition of Nitroblue Tetrazolium (Nbt) reduction. Clin Chim Acta. 1993;214:103-4.

69. Shan DP, Huang JG, Yang YT, Guo YH, Wu CA, Yang GD, et al. Cotton GhDREB1 increases plant tolerance to low temperature and is negatively regulated by gibberellic acid. New Phytol. 2007;176:70-81.

70. Bailey RW. The reaction of pentoses with anthrone. Biochem J. 1958;68:669-72.

\section{Publisher's Note}

Springer Nature remains neutral with regard to jurisdictional claims in published maps and institutional affiliations.

Ready to submit your research? Choose BMC and benefit from:

- fast, convenient online submission

- thorough peer review by experienced researchers in your field

- rapid publication on acceptance

- support for research data, including large and complex data types

- gold Open Access which fosters wider collaboration and increased citations

- maximum visibility for your research: over $100 \mathrm{M}$ website views per year

At $\mathrm{BMC}$, research is always in progress.

Learn more biomedcentral.com/submissions 